\title{
Researchon Regenerative and Dynamic Braking Performance in Motor Application
}

\author{
Ramaswami.S, Sundar.R
}

\begin{abstract}
This paper presents the analysis of the different braking system and fed into the motor application. Electric braking plays a major role in the working of electric vehicles the performance development, energy utilization. So the braking system is used to enhance the performance of the motor. Here the analysis of regenerative and dynamic braking performance in an induction motor.In energy generation context, regenerative braking is very proficient. On the other hand in dynamic braking, the energy will not fed back to the source, but the performance of regenerative braking is the generated power fed back to the source. Control techniques have used to utilize the energy efficiency of regenerative braking and analysis their performance in regenerative braking. In this study, comparison has been made between the utilization of regenerated power in dynamic braking and regenerative braking.
\end{abstract}

Keywords: Electrical braking, induction motor, regenerative braking, dynamic braking.

\section{INTRODUCTION}

Research and development of intelligent vehicles have much attention due to the growing foreboding about global warming, fossil fuel shortage, as well as passenger vehicle safety[1-3]. On the other hand, the high cost of Electrical Vehicle's (EV)/Hybrid Electrical Vehicle's (HEV) has set them in a wide range. There is a complexity of bidirectional power-flow which leads to an increase in the cost of an electric vehicle. For this above reason, the researchers and developer are focused on making it eco-friendly for that simplifying the configuration of an electrical vehicle. For smooth control of a motor, braking is essential for machines. Performance of braking is the unease in the design mechanical system. Every designed braking system always meets the distinctive demand of response of motor, maintaining the motor direction and maintaining the energy recovery of the system. To rectify the above distinctive demand motor are equipped with a braking system [4-8]. There are two types of braking well equipped with motor namely mechanical braking and electrical braking. Accurate, smooth control and sudden stopping of the motor may not be suitable in mechanical methods than electrical methods. Electrical braking employed in the electrical drive can be classified into three types: plugging (counter current braking), dynamic braking (rheostatic braking), and regenerative braking. The method of plugging had enough efficient, but there was no regeneration of the kinetic energy into electrical energy that will store in the battery during the process of braking. The disadvantage of plugging is that

Revised Manuscript Received on April 12, 2019.

Ramaswami.S, Assistant Professor, Dept of Naval Architecture and offshore Engineering, AMET Deemed to be University, Chennai, Tamil Nadu, India.

Sundar.R, Assistant Professor, Dept of EEE, AMET Deemed to be University, Chennai, Tamil Nadu, India. some amount of power dissipated during plugging. This dissipated energy in plugging braking can overcome by other methods [8-10]. Improved energy efficiency methods in electric vehicles are dynamic and regenerative braking. During the process of dynamic braking regenerated energy could not send to the source and it will dissipate through heat, but in regenerative braking, power is directly restored into the battery which improves the overall energy efficiency [11-12]. Here, in this survey analysis the performance of regenerative braking with dynamic braking.

In conventional, verify and implement the performance of induction motor using various control strategy with plugging and regenerative braking. This survey, we study the performance of induction motor using various control methods with dynamic and regenerative braking. The induction motor is selected for application of electric vehicle and hybrid electric vehicle. An induction motor has following property like reliable, less maintenance, easy to work, and less cost. So that induction motor is used widely in electric vehicle application [13]. For smooth operation of vehicle it will increases the energy recovery of the motor we need effective regenerative braking system. Study the energy recovery efficiency of the motor using regenerative braking. Reverse direction of power stored in a battery that will show in\% State of Charge (SOC) [14-15]. In this study divided into the motoring mode, generating mode, and braking mode of the induction motor.

\section{MODES OF MACHINE}

\subsection{MOTORING MODE}

Generally, the machine may operate at either motoring mode or generating mode. Figure 1 represents the operating modes of the machine. There is four possible mode of the induction motor. In mode (I\&III) are motoring modes of the machine. Motoring mode of the machine is nothing but reversal operation of generating mode.The motor converts electrical power from the source into mechanical energy for the required application.

\subsection{GENERATING MODE}

In this generating mode, the motor acts as a generator to convert the mechanical power of the shaft into electrical power to the source. When the induction motor disconnect from the source it will start to generate power.If the rotor speed is higher than the synchronous speed that mode is called generating mode of the induction motor. In mode (II $\&$ IV) are generating modes of the machine. Figure 2 represents the operating characteristics of an induction motor.

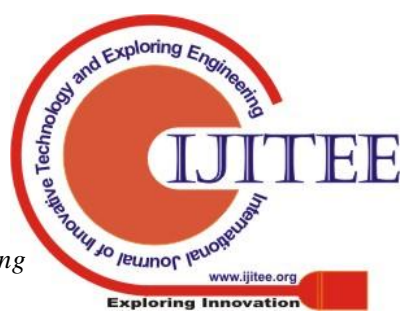




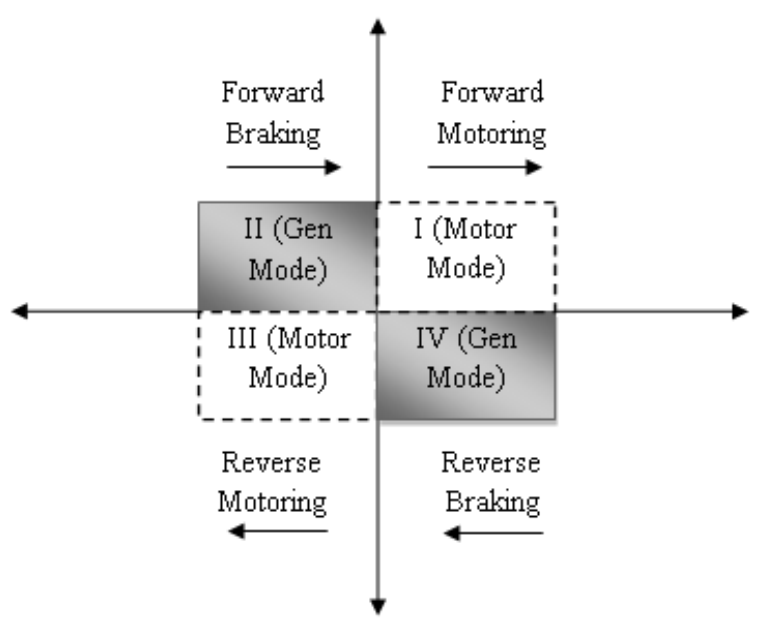

Figure 1 Operating modes of motor

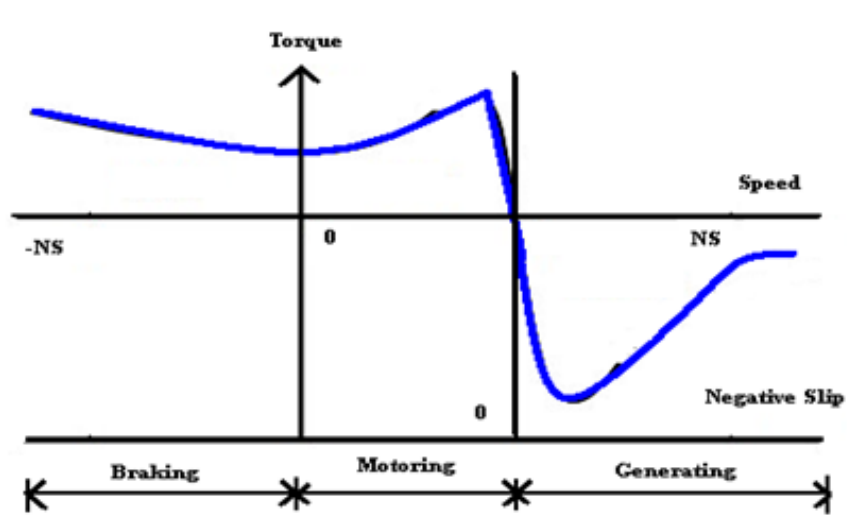

Figure 2 Operating characteristics of the induction motor

\subsection{BRAKING MODE}

Braking is the method of reducing the speed of the motor due to the dissipation of energy. Braking of motors can be classified into three types namely plugging (counter current braking), dynamic braking, and regenerative braking. This braking system is consummate with the induction motor.

\subsubsection{PLUGGING or COUNTER CURRENT BRAKING}

It is the process that is deducing the speed of the running motor due to interchanging the connection of phase in the stator with respect to supply. Due phase reversal, the direction of rotating field also reversed.The main advantage of plugging is a quick response even though it has some drawback there is no regeneration of the mechanical energy into electrical energy that will store in the battery, I2R losses are high that occurs in the form of heat during plugging.Due heat produces in the rotor which damage the rotor bar and stator. So, we move on another type of braking like dynamic braking, regenerative braking and so on for improving the performance of the motor.

\subsubsection{DYNAMIC BRAKING}

Dynamic braking is otherwise called as rheostatic is mandatory to decrease the speed of the motor. Dynamic braking is achieved by the machine when the machine acts as a generator. In this type, the motor acts as a generator and generates energy. Here the function of the generator is to convert rotational energy into electrical energy. Generated power dissipated in the form of heat across resistor. Braking time $(\mathrm{t})$ of the motor is directly proportional to the value of the resistor. While comparing the performance of dynamic braking is better than plugging braking. Because of dynamic braking requires low wear of components, highly reliable, and control of the motor with safe value. It also has some drawbacks are only applicable for low-speed application and generated power will not use in future, it will dissipate in the form of heat. Figure 3 represents the block diagram of control and performance of dynamic braking of the motor.

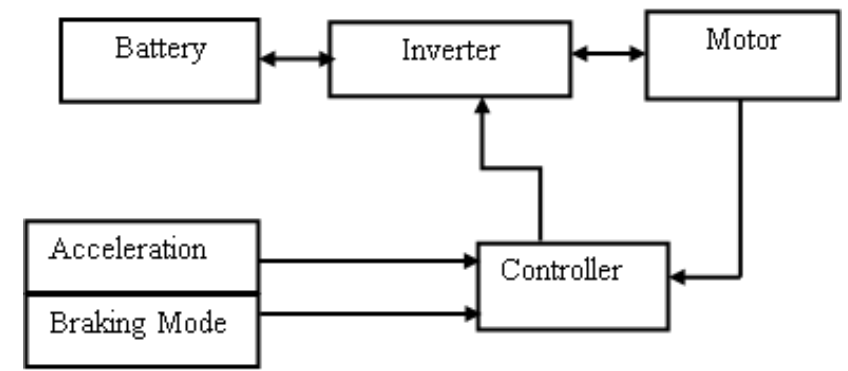

Figure 3 Block diagram of control and performance of dynamic braking of the motor

\subsubsection{REGENERATIVE BRAKING}

The function of regenerative braking is similar to dynamic braking.Generated power stored in the source; this is dissimilar from dynamic braking. The main advantage of this braking is generated power utilized beneficially compare to dynamic braking. The two terminal phase reversal of current can achieve regenerative braking during discharging and charging the current flow into the supply battery. Charging and discharging can be attained at single stage operation of DC/AC converter which is used to drive the motor. This paper proposes performance braking system for an induction motor drive for an electrical vehicle-based application. The induction motor fed single stage bidirectional converter is shown in Figure 4.System module consists of battery, inverter, and motor and control strategy. Acceleration and braking command are applied to the drive system at various conditions.Command can be classified into two types they are acceleration command and braking command.During brake mode, the acceleration is inactive.During acceleration mode, the brake is idle.

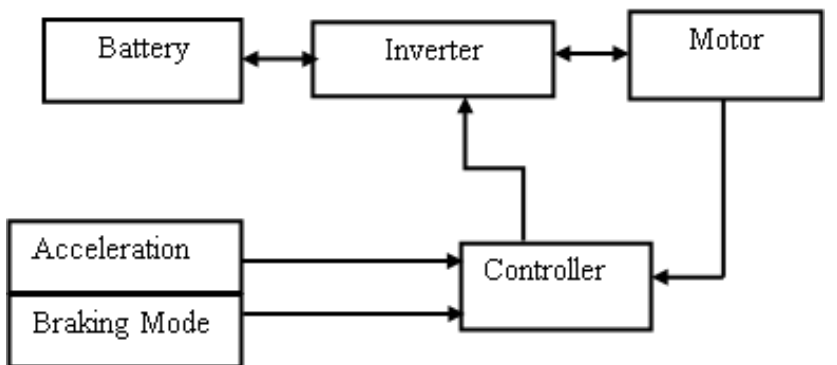

Figure 4 Block diagram of control and performance of regenerative braking of the motor 


\section{PERFORMANCE OF REGENERATIVE BRAKING}

In conventional $\mathrm{V} / \mathrm{F}$ control algorithms are proposed in the literature for proper selection, and improve the performance between dynamic and regenerative braking. In this proposed survey regenerative braking has been implemented with field oriented control for enhancing the performance of the motor. For proper functioning of regenerative braking requires some additional controllers. Even in the conventional method, several controller methods were implemented like PI, PID, and Fuzzy logic controller to improve the efficiency of the motor. Two methods are used to realize the implementation of regenerative braking. There are speed control and torque control.In speed control based regenerative braking is the speed of the rotor is higher than synchronous speed. At that time negative slip will occur. Due to negative slip to brakes the motor and it decelerates until it reaches to rest position. When the regenerative braking is started, speed control of the motor is stopped. Under torque control method a larger amount of energy will generate. Generated power is stored in a battery. Charging and discharging of the battery during regenerative mode is represented in the graph.During speed control mode $\%$ SOC of the battery decreases linearly and in torque control mode \%SOC of battery increases linearly with respect to time (sec). This process was repeated for a different speed.Maximum energy is utilized during this regenerative braking.It increases the efficiency may be (75\%-85\%) of the motor performance than implementing the dynamic braking.

\section{RESULTS \& DISCUSSIONS}

In dynamic braking, the discharging level of the battery can be represented in \% State of Charge. During braking mode, there is no regeneration, and there is no reversal of power. So, $\%$ of SOC decreases $(70 \%-69.90 \%)$ linearly but in regenerative braking power will be generated.It has motor acts as a motor as well as a generator. During motoring mode, the voltage level of battery decreases and in generating mode voltage level of battery increases. From this comparison analysis, regenerative braking utilize the energy effectively. So that regenerative braking is equipped with any motor applications. Figure 5, 6 represents the $\%$ SOC of the battery during dynamic and regenerative braking.

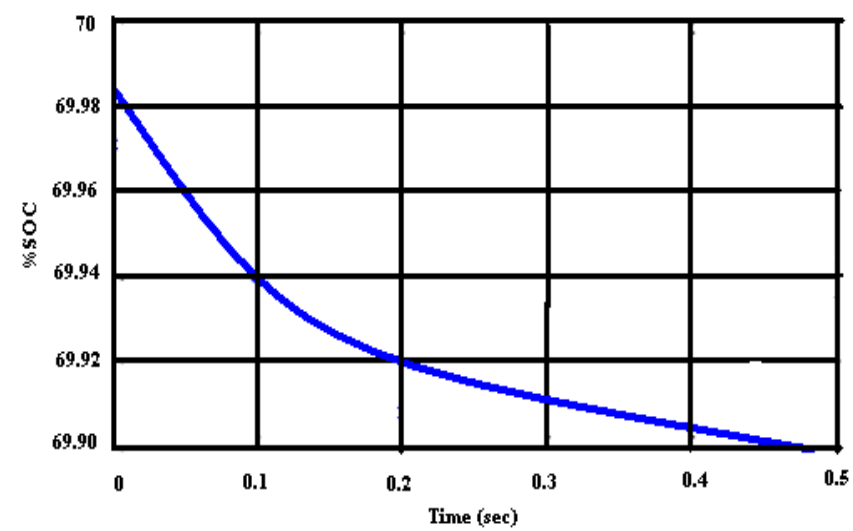

Figure $5 \%$ SOC during dynamic braking

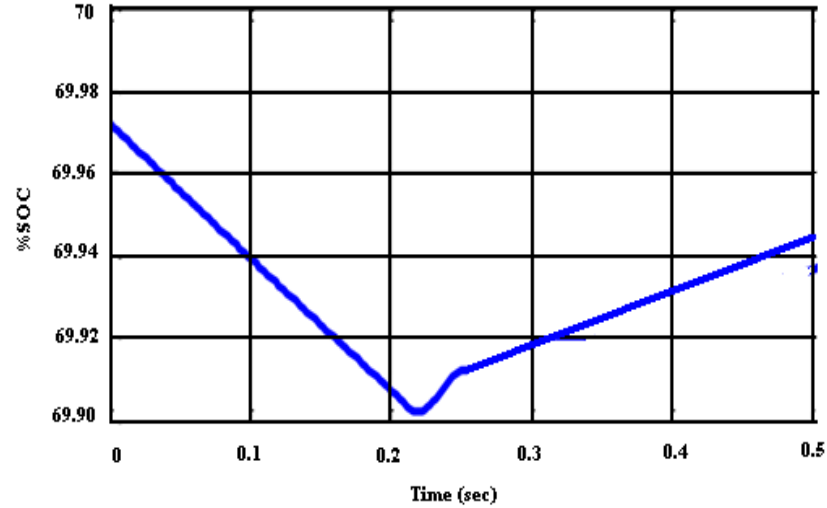

Figure $6 \%$ SOC during regenerative braking

\section{CONCLUSION}

In this survey, a comparison had made between the utilization of regenerated power in dynamic braking and regenerative braking. In regenerative braking, there is no wear of components. The performance of both dynamic braking and regenerative braking method is conducted separately for SOC and speed.This survey carried out the effectiveness of regenerative braking under various methods.Maximum energy is utilized during this regenerative braking.It increases the efficiency may be (75\%-85\%) of the motor performance is efficient than implementing the dynamic braking.

\section{REFERENCE}

1. Godfrey AJ, Sankaranarayanan V. A new electric braking system with energy regeneration for a BLDC motor driven electric vehicle. Engineering Science and Technology, an International Journal. 2018 Aug 1; 21(4):704-13.

2. Nian X, Peng F, Zhang H. Regenerative braking system of electric vehicle driven by brushless DC motor. IEEE Transactions on Industrial Electronics. 2014 Oct; 61(10):5798-808.

3. Joshi PR, Dubey GK. Optimum DC dynamic braking control of an induction motor using thyristor chopper controlled resistance. IEEE Transactions on Industrial Electronics and Control Instrumentation. $1974 \operatorname{May}(2): 60-5$.

4. Ko J, Ko S, Bak Y, Jang M, Yoo B, Cheon J, Kim H Development of regenerative braking co-operative control system for automatic transmission-based hybrid electric vehicle using electronic wedge brake. World Electric Vehicle Journal. 2013 Jun; 6(2):278-82.

5. Demerdash NA, Nehl TW. Dynamic modeling of brushless DC motors for aerospace actuation. IEEE Transactions on Aerospace and Electronic Systems. 1980 Nov(6):811-21.

6. Plunkett $A B$, Plette DL. Inverter-induction motor drive for transit cars. IEEE Transactions on Industry Applications. 1977 $\operatorname{Jan}(1): 26-37$.

7. Okazaki Y, Shioda S, Akagi H. Performance of a distributed dynamic brake for an induction motor fed by a modular multilevel DSCC inverter. IEEE Transactions on Power Electronics. 2018 Jun;33(6):4796-806.

8. Barkand TD, Helfrich WJ. Application of dynamic braking to mine hoisting systems. IEEE transactions on industry applications. 1988 Sep;24(5):884-96.

9. Powell BK, Bailey KE, Cikanek SR. Dynamic modeling and control of hybrid electric vehicle powertrain systems. IEEE Control Systems Magazine. 1998 Oct;18(5):17-33. 
10. Yang SM, Chen JY. Controlled dynamic braking for switched reluctance motor drives with a rectifier front end. IEEE Transactions on Industrial Electronics. 2013 Nov;60(11):4913-9.

11. Fazeli A, Zeinali M, Khajepour A. Application of adaptive sliding mode control for regenerative braking torque control. IEEE/ASME Transactions On Mechatronics. 2012 Aug;17(4):745-55.

12. Duran MJ, Gonzalez-Prieto I, Barrero F, Levi E, Zarri L, Mengoni M. A simple braking method for six-phase induction motor drives with unidirectional power flow in the base-speed region. IEEE Transactions on Industrial Electronics. 2017 Aug;64(8):6032-41.

13. Naseri F, Farjah E, Ghanbari T. An efficient regenerative braking system based on battery/supercapacitor for electric, hybrid, and plug-in hybrid electric vehicles with BLDC motor. IEEE Transactions on Vehicular Technology. 2017 May;66(5):3724-38.

14. Xu G, Xu K, Zheng C, Zhang X, Zahid T. Fully electrified regenerative braking control for deep energy recovery and maintaining safety of electric vehicles. IEEE Transactions on Vehicular Technology. 2016 Mar;65(3):1186-98.

15. Ko JW, Ko SY, Kim IS, Hyun DY, Kim HS. Co-operative control for regenerative braking and friction braking to increase energy recovery without wheel lock. International journal of automotive technology. 2014 Mar 1;15(2):253-62.

16. Vettriselvan R., Ruben Anto., \&JesuRajan FSA (2018), Rural lighting for energy conservations and sustainable development, International Journal of Mechanical Engineering and Technology, 9(7):604-611. 